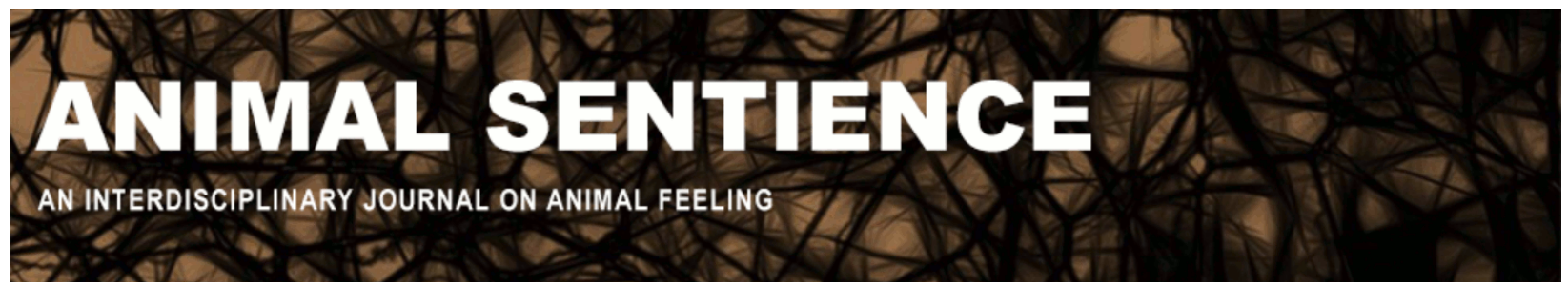

Mather, Jennifer A. and Carere, Claudio (2016) Cephalopods are best candidates for invertebrate consciousness. Animal Sentience 9(2)

DOI: $10.51291 / 2377-7478.1127$

Date of submission: 2016-07-18

Date of acceptance: 2016-07-27

(c)

This article has appeared in the journal Animal

Sentience, a peer-reviewed journal on animal

cognition and feeling. It has been made open access,

free for all, by WellBeing International and deposited

in the WBI Studies Repository. For more information,

please contact

wbisr-info@wellbeingintl.org.

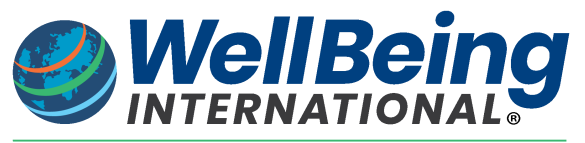

SOLUTIONS FOR PEOPLE, ANIMALS AND ENVIRONMENT 


\title{
Cephalopods are best candidates for invertebrate consciousness
}

\author{
Mather \& Carere on Klein \& Barron on Insect Sentience
}

Jennifer A. Mather

Department of Psychology, University of Lethbridge, CA

\section{Claudio Carere}

Department of Ecological and Biological Science, University of Tuscia, Italy Laboratory of Experimental and Comparative Ethology, University Paris 13, Sorbonne Paris Cité, France

\begin{abstract}
Insects might have been the first invertebrates to evolve sentience, but cephalopods were the first invertebrates to gain scientific recognition for it.
\end{abstract}

Keywords: consciousness, sentience, animal welfare, invertebrates, cephalopods

Jennifer A. Mather does field work on the behaviour of cephalopod molluscs (octopus and squid) and laboratory studies on the cognitive abilities of the octopus. She also studies the attitudes of students to invertebrates $199 \%$ of the animals on the planet) to see whether their negative views can be changed. http://directory.uleth.ca/users/mather

Claudio Carere does research on individual differences in animal behaviour and physiology, hormonal correlates of behaviour, animal personality, collective behaviour, and animal welfare. https://www.researchgate.net/profile/Claudi o_Carere
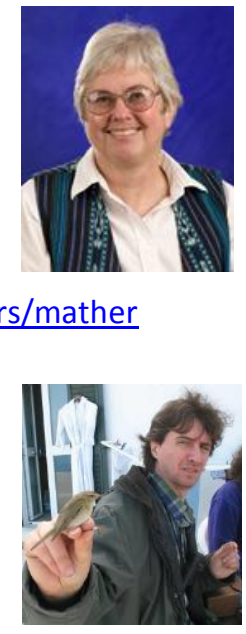

Barron and Klein (2016; Klein \& Barron 2016) discuss the origins of consciousness in invertebrates, focusing on insects. They use a neuroethological approach to assess insects' capacity for subjective experience. Singling out the insect cephalic ganglion, they explore insects' neural modeling of space. Moving "beyond insects," they go on to cover box jellies and nematodes, but surprisingly they omit the most likely example of consciousness in invertebrates: Cephalopod molluscs have large central brains and flexible behavior. Based on neural and behavioral evidence including lateralization of the brain, tool use, spatial memory and navigation, concept formation and even personality and sense of self, Mather (2007) has suggested that cephalopods are capable of subjective experience and that they use the global workplace outlined by Baars (1997) and also mentioned by Klein and Barron.

Based partly on this evidence, a group of prominent neuroscientists declared in 2012 that consciousness is not confined to mammalian neural structures and that "[n]on-human animals, including all mammals and birds, and many other creatures, including octopuses, 
also possess these neurological substrates" (Low 2012). Whereas insects too may be candidates for inclusion in the category of sentient animals, cephalopods have already been accepted as such by these neuroscientists; hence it is surprising that the present authors ignored this declaration. Further evidence for subjective experiences would be provided by pain, which is by definition a subjective experience.

Alupay and colleagues (2015) have published the latest in a series of studies on cephalopods looking for behavioral evidence of such experiences. They observed immediate wound tending, longer term arm guarding, and 24-hour withdrawal from touch along with long-term sensitization in nerves, causing both local and general lowering of sensory thresholds. They cautiously concluded that pain was difficult to prove, suggesting that this might be a case of immediate sensory nociception. Evidence for cephalopods' advanced cognitive capacity is presented in the chapters of Cephalopod Cognition (Dickel et al. 2014), including sensitive periods for learning, neural representation of space, play, and the use of visual information for camouflage.

A further consequence of this growing evidence of consciousness in cephalopods is an increasing recognition of the need to consider their welfare in animal experimentation (Berry et al. 2015). In Canada, cephalopods have been granted consideration of welfare in animal experimentation equal to that of vertebrates since 1991. After a long process of consultation, the European Union's revised animal welfare regulations also concluded in Directive 2010/63/EU Article 1, 3b that cephalopods deserve protection based on "a review of the evidence for sentience and capacity to experience pain, suffering, distress and lasting harm." Fiorito et al. (2015) accordingly generated a detailed set of guidelines for their care and welfare.

\section{References}

Alupay, J., Hadjisolomou, S.P., and Crook, R.J. (2014) Arm injury produces long-term behavioral and neural hypersensitivity in octopus. Neurosci. Lett. 558, 137-142

Baars, B.J. (1997) In the theatre of consciousness: Global workplace theory, a rigorous scientific theory of consciousness. J. Conscious. Stud. 4, 292-309

Barron, A.B., and Klein, C. (2016) What insects can tell us about the origins of consciousness. Proc. Natl. Acad. Sci. USA 113, 4900-4908

Berry, A., Vitale, A., Carere, C., and Alleva, E. (2015) EU guidelines for the care and welfare of an "exceptional invertebrate class" in scientific research. Ann. Ist. Sup. Sanità 51, 274-276

Dickel, L., Darmaillacq, A.-S., and Mather, J.A. (2014) Cephalopod Cognition. Cambridge University Press, Cambridge

Fiorito, G., Affuso, A., Basil, J., Cole, A., de Girolamo, P., D’Angelo, L., Dickel, L., Gestal, C., Grasso, F., Kuba, M., Mark, F., Melillo, D., Osorio, D., Perkins, K., Ponte, G., Shashar, 
N., Smith, D., Smith, J., and Andrews, P.L.R. (2015) Guidelines for the care and welfare of cephalopods in research - a consensus based on an initiative by CephRes, FELASA and the Boyd group. Lab. Anim. 49, 1-90

Klein, C., and Barron, A. B. (2016) Insects have the capacity for subjective experience. Animal Sentience 2016.100

Low, P. (2012) The Cambridge Declaration on Consciousness. Francis Crick Memorial Conference on consciousness in human and non-human animals, Churchill College, Cambridge

Mather, J.A. (2007) Cephalopod consciousness: behavioral evidence. Conscious. Cogn. 17, $37-48$ 